\title{
A Systematic Review of Structure, Culture, and Demography of New Public Management (NPM) in the Developing Countries
}

\author{
Antony Wafula Wanyonyi \\ School of International Exchange, Nanjing Audit University, 86 West Yushan Road, Nanjing, China, 211815
}

\begin{abstract}
The paper assesses the effectiveness of NPM and its impacts with key consideration to culture, structure, and demography of developing nations. It blends the literature with cases and publications from the global organizations such as World Bank, United Nations, and International Monetary Fund (IMF). The study analyses the NPM reforms in Kenya which include budgeting, institutionalization and financial reporting, use of information systems, and changes in the management public finance. Increased transparency and accountability, public expenditures, and creation of agency problems are identified as the main impact of NPM on public governance. The literature also reveals that effective judicial system; efficient and control-oriented administrative system; and state capacity are some of the preconditions for NPM model. Onto to the factors affecting NPM implementation in the developing nations; it was found that limited resources, dispositions, the professional society, bureaucratic structure are the primary players. The article recommends institutionalization of code of ethics, balancing politics and bureaucracies, effective law enforcement, and implementation of NPM principles in phases as strategies to eliminate risk of failure. It then concludes that with increased pressure from the international donors, developing countries will continue adopting NPM framework into their public administrative systems.
\end{abstract}

Keywords: NPM, public sector, institutionalization, bureaucracy, transparency and accountability, performancebased budgeting, organizational structure and culture.

DOI: $10.7176 / \mathrm{DCS} / 9-12-06$

Publication date: December $31^{\text {st }} 2019$

\section{Introduction}

\subsection{Background Information}

The public management in both developed and developing countries has undergone substantial changes over the past two decades. In earlier 1960s, the system was characterized by rule-based, policy-administration, hierarchy, division of labor and career systems (Pollitt et al., 2007). The systems came under criticisms in 1970s for a variety of reasons such as fiscal crises, corruption, and lack of accountability among government officials, imperial bureaucracy, poor performance, and changes in the citizens' expectations (Sarker, 2006; Mathiasen, 1999). The increased challenges and demands from the public gave rise to the New Public Management (NPM).

The framework advocates for service quality, cost efficiency, coordination, coherence of policies, and equal access to public resources (Hammerschmid et al., 2017). According to Haque (2006), NPM aims at making the public sector lean and more competitive while, at the same time, trying to make it more responsive to the needs of the citizens by ensuring value for money, transparency and creating flexible options. After its inception in the United States, the United Kingdom, and other developed nations; the framework has gained popularity. As a result, many developing countries have followed the path or been pressured by the international donor organizations to adopt and implemented the NPM logic into their administrative systems.

NPM Defined

Pollitt et al. (2007) defines New Public Management (NPM) as a heterogeneous set of management techniques and methods that focus on reducing bureaucracies in the large public sector. It entails the division of large organizations of the public sector into smaller units accompanied by market competitiveness within the environment of private entities (Haque, 2006).

\subsection{Problem Statement}

Since its inception, the NPM model has been a center of debate in the literature relating to the public administration, public management, and public sector accounting such that scholars have come up with different views and perceptions regarding its constitutes or elements. There is need to find a common ground for a perfect implementation process. Secondly, the new framework promises a better government, improved service delivery, empowerment, decentralization, clientele satisfaction, transparency and accountability (Sarker, 2006; Pollitt et al., 2007). But there are questions that need to be answered such as how can countries especially the developing ones can achieve such outcomes? What are the requirements that need to be fulfilled? Most studies have focused on the developed economies and made assumptions that strategies applied in these nations can as well be applied in the evolving economies. As Groot \& Budding (2008) put it, different nations face difference problems and apply different strategies or ideas to have them resolved. Therefore, this paper examines the factors that determine the success or failure NPM model in relation to culture, structure and demography in the developing nations with 
Kenya as an example.

\subsection{Research Questions}

The article reviews the literature so as to answer the following questions.

- What are the preconditions or requirements that countries or governments should meet for the NPM model to be successful?

- What are the potential effects of NPM on Public Governance?

- What are the factors affecting the implementation of NPM reforms in the developing countries

\subsection{Research Objectives}

The purpose of the article is to assess the effectiveness of NPM and examine its impacts while considering culture, structure, and demography of developing nations. In order to fulfill the aim, the following objectives were formulated to support the analysis.

- To evaluate the preconditions for the success of NPM model

- To determine the potential impacts of NPM on public governance

- To identify and describe the factors affecting the implementation of NPM model in the developing countries

- To analyze the NPM reforms in Kenya

- To provide recommendations and suggestions for the adoption and implementation of NPM elements in the developing economies

\subsection{Significance of the Study}

Public management is a central issue in any country. It is not only a concern to the politicians, civil servants, and public administrators, but to the public as a whole. Most developing nations have faced difficulties in implementing the reforms suggested by the NPM model. Some have incorporated the strategies applied by developed economies which have resulted into total failure due to cultural, structural, and demographic differences. By putting into account these elements, the paper outlines the key success factors that help the developing countries to effectively put into practice the proposed amendments. It also aids the planning processes by defining the pre-requisites for the success of NPM. Most countries operate on constrained budgets. By assessing the preconditions and the possible effects of NPM, the article helps nations to save resources and ensure effectiveness of the adopted reforms by concentrating on the key areas that are more likely to benefit the entire public. Through the case analysis of some emerging economies such as Singapore, the paper offers additional insights and strategies that other developing countries can use to improve public administration.

\subsection{Research Design and Procedures}

The study reviews the scholarly articles which include previous researches regarding the adoption and implementation of NPM-archetype countries such as United States, United Kingdom, New Zealand, Australia, and Canada among other European nations. Based on the collected information as covered by the literature, the study compares the status of NPM in developed economies with NPM-importer countries of which majority are developing economies such as Nigeria, Ghana, Singapore and Kenya. The Comparison brings out the differences that are then relied upon to point out the factors affecting these nations. Articles reviewed and published within the past the years. This was in effort to provide the most current status of NPM across the world. Nonetheless, some journals published more than ten years ago were considered to offer a concrete historic background of the framework.

Periodicals and publications by the widely recognized organizations such as the World Bank, United Nations and the International Monetary Fund (IMF) were also consulted to obtain the most current blueprint of NPM in different nations across the world and the way forward. It should also be noted that these organizations play a huge role in setting economic objectives for the member states hence reliable sources for this study. Besides that some such as IMF strongly support NPM and encourage developing nations to adopt it into their system. The analysis also incorporates assessment of cases studies and observations in which Kenya, one of the developing countries was a center of focus. It also takes into account the neighboring countries including Tanzania and Uganda. The cases formed the primary basis over which recommendations and suggestions for effective and efficient implementation of NPM in most developing nations were made.

\section{Theoretical Framework}

This section presents the historical background of NPM; its main elements/features; and the change processes.

\subsection{Historical Background of NPM}

The developments of New Public management began in late 1970s through earlier 1980s in the United Kingdom 
and some Municipal council in the United States. This was after suffering economic recessions, crises, and tax revolts (Gruening, 2001). In the UK, Prime Minister Margaret Thatcher propounded the changes under the burner 'the Financial Management and Next Steps initiatives.' The Australian and New Zealand governments soon followed and the success stories made the changes to be a center of focus for other countries (Groot \& Budding, 2008). However, it was not until earlier 1990s that Owen Hughes and Christopher Hood defined and coined NPM model with specific features and elements.

From a theoretical point of view, NPM has been influenced by different ideas from a variety of disciplines such as management theory, public-choice theory, classical and neoclassical public administration, principal-agent theory, and policy analysis (Gruening, 2001). The ideas can be broadly classified into three groups. First, management science, advocated for the introduction of the management ideas in the private sector into the public management (Gruening, 2001; Groot \& Budding, 2008). Classical public management/administration as the second category called for the application of scientific principles and collective decision making (Gruening, 2001). Lastly, new institutional economics focused on reducing agency and transaction costs resulting from the information asymmetry between the management and the citizens (Groot \& Budding, 2008). The three orientations introduced particular themes and objectives of NPM agenda depending on the needs of the country.

\subsection{The Main Features and Elements of NPM}

Due to differences in opinion and the needs of each country, scholars from different backgrounds have pointed out different features of NPM they feel are more important. Pollitt (2001) holds that there a number of NPM elements that are accepted by most proponents. Among them include a shift of management systems from processes and inputs to outputs, outcomes and greater measurements based on performance (Pollitt, 2001). In his article, he advocates for contracting out, establishment of lean and autonomous forms of public organizations instead of "large, multi-purpose, hierarchical bureaucracies" (Pollitt, 2001). He also points out inter-relationships between private and public sectors; and use of market-oriented mechanisms in the public administrations to satisfy the needs of the citizens.

Gruening (2001) also identifies varies characteristics of NPM that are echoed by Pollitt et al., (2007); Hammerschmid et al., (2017); Groot \& Budding, (2008). He classifies into two groups: undisputed and disputed. The undisputed ones include performance measurement and auditing; strategic planning and management; separation of politics and public administration; personnel management; competition, privatization, contracting out, budget cuts, and freedom of management for managers (Gruening, 2001). In his theory, Christopher Hood argues that professionals in the public sector should be given autonomy to work freely and be allowed to apply their own strategies to achieve the set goals (Hammerschmid et al., 2017). NPM emphasizes on setting target and performance assessment criteria to measure the output in relation to the inputs (Gruening, 2001). Besides the introduction of market principles or private sector management style in public administration, NPM shifts the paradigm to great competition. It introduces a tendering system that promotes competition and justified application of rivalry as a key to obtain desirable results (Pollitt et al., 2007).

Owen Hughes holds that NPM is characterized by changing the structure of public management with the aim of achieving public purpose. Some of the proposed changes include introduction of new technologies, skilled workers and focusing on market oriented practices (Mathiasen, 1999). According to Groot \& Budding (2008), separation of politics and administration should be a priority when implementing NPM reforms. Rather than working to meet the interests of public officials and politicians, the amendments focus on satisfying the needs of the public just like the private sector operates to satisfy its clients (Groot \& Budding, 2008). The state or the government acts as the facilitator and enabler to bring in more market players and efficiently channel the market forces (Gruening, 2001). NPM looks forward to making the system more friendly to the citizens or client-oriented through agreements that allow the corridors of power to work independently but remain accountable of their decisions and actions (Groot \& Budding, 2008). NPM is also characterized by personnel management through incentives and rewards to encourage them to offer services of high quality to the public. According to Gruening (2001), improved regulation; the rationalization of jurisdictions; democratization and enhancement of citizen participation are some of NPM features that are still debatable.

Diefenbach (2009) categorizes NPM elements into 5 areas: business environment and strategic objectives; organizational structures and processes; performance management and management systems; management and managers; employees and corporate culture. Key elements in each area are summarized in the table below 
Table 1: NPM Elements according to Diefenbach (2009)

\begin{tabular}{|c|c|}
\hline Area & Key Elements \\
\hline $\begin{array}{l}\text { Business Environment and } \\
\text { Strategic Objectives }\end{array}$ & $\begin{array}{ll}- & \text { Strong external pressure } \\
\text { - } & \text { Organizational change in accordance to large trends and forces } \\
\text { - } & \text { Market-orientation: value-for-money approach } \\
\text { - } & \text { Stakeholder-orientation: Meeting the public interests } \\
\text { - } & \text { Customer-orientation: delivering services from a client perspective } \\
\text { - } & \text { Competitive tendering, cost-reduction, outsourcing, downsizing, and } \\
\text { privatization. }\end{array}$ \\
\hline $\begin{array}{l}\text { Organizational Structures } \\
\text { and Processes }\end{array}$ & $\begin{array}{ll}- & \text { Decentralization, flexibility, and less hierarchy } \\
\text { - } & \text { Standardization and formalization of management processes } \\
\text { - } & \text { Cross-boundary collaboration }\end{array}$ \\
\hline $\begin{array}{l}\text { Performance Management } \\
\text { and Measurement Systems }\end{array}$ & $\begin{array}{ll}- & \text { Performance indicators, standards and control systems } \\
- & \text { Increased efficiency, productivity, quality, performance, and motivation }\end{array}$ \\
\hline Management and Managers & $\begin{array}{ll}- & \text { Establishment of a managerial culture } \\
- & \text { Freedom of management or decision making }\end{array}$ \\
\hline $\begin{array}{l}\text { Employees and Corporate } \\
\text { culture }\end{array}$ & $\begin{array}{ll}- & \text { Entrepreneurial spirit } \\
- & \text { A new corporate culture } \\
- & \text { Staff empowerment and subsidiarity }\end{array}$ \\
\hline
\end{tabular}

\subsection{NPM Change Processes in the Public Management}

Public administration and management is the central focus for the NPM movement. Ashraf \& Uddin (2016); Lapsley (2008) and Diefenbach (2009) discuss four key NPM change mechanisms that have been supported by other studies: Introduction of general managers; entrepreneurship in the public sector; structural Reforms and introduction of performance measures.

\subsubsection{General Managers}

The high NPM proponents' countries such as the UK and New Zealand emphasized on replacing the old public administrators with general managers as change agents. The phenomenon was first coined in the UK in earlier 1980 where Chief Executive Officers (CEOs) were appointed to be in charge of public institutions (Van \& Hammerschmid, 2011). Later, the aspect became one of the main precursors of NPM. In his study Boston et al., (1996) as cited by Lapsley (2008) find that the managers played a significant role in transforming the public sector of New Zealand.

People are regarded as the main mechanism of the New Public Management. (Oehler-Sincai (2008) refers for this kind of relationship as "people for people." The success of NPM calls for competent and committed managers who can implement policies and offer services to the public in an effective, efficient, ethical way and still remain responsible and accountable of their decisions or actions (Oehler-Sincai, 2008). The managers should maximize output by minimizing costs and through good work practices. They should be fair and honest; satisfy the public with quality; keep them updated or fully informed and taking the citizens needs as priority. With NPM in practice, the leadership should focus on activities that have positive impacts or outcomes while giving up all the operations that maybe harmful for the society, economy, or the environment (Fatemi \& Behmanesh, 2012). The element is believed to easy decision making because it does not accommodate conflicts of interests. However, it has attracted some criticism Mongkol (2011) states the paradox of general managers encourages centralization through decentralization. Citing Maor (199) and Kabolian (1998), he argues that more authority in the hands of public managers preserve a lot of rights to make decisions rather than allowing a participative process (Mongkol, 2011). It is thus recommendable maximum degree of flexibility be considered when implementing general management to avoid the state of mechanistic management hierarchies (Lapsley, 2008).

\subsubsection{Entrepreneurship in the Public Sector}

The aspect is seen as a way of reinventing the government. The fiscal crises and the multiple challenges experienced by the US and the UK governmental institutions called for entrepreneurial management (Ashraf \& Uddin, 2016). The demand for creative and innovative techniques to provide public services led to the suggestion of entrepreneurship. Lapsley (2008) also holds that social entrepreneurship is advocated in the public administration as a mean of addressing the unresponsiveness and inflexibility of government bureaucracies. The attribute is said to be beneficial and economical as it enhance the use of limited resources in way to promote effectiveness and efficiency (Ashraf \& Uddin, 2016).

The analysis by the United Nations identifies Singapore as one of the developing countries that have strengthened its public administrations through NPM and more specifically through entrepreneurship. The government set up a Public Service for the $21^{\text {st }}$ Century (PS21) to "nurture high standards of public service excellence and responsiveness, and to foster an environment of innovation and continuous improvement" (Robinson, 2015). It also created a platform (the Centre for strategic Futures Group) for engagement with external 
stakeholders across departments when formulating long-term strategies (Robinson, 2015). The country has also additional success strategies that can be borrowed by developing countries. Among them include strong antcorruption measures, fostering integrity, result-oriented such that payment and promotions are subject to individual's performance. Competitive salaries for the public servants as way of coping corruption are another strategy worthy borrowing.

\subsubsection{Structural Reforms}

The nature of organization forms and the context in which they operate include monitoring of activities and operations in the public sector and mechanisms for the allocation of resources (Lapsley, 2008). According to Ashraf \& Uddin (2016), structural reforms start with changes in the policies. The amendments include creation of market-like structures. For instance UK started by establishing quasi or internal market in the National Health Service (NHS) in the year 1991(Lapsley, 2008). The markets were further amended in 1997 to include more players. Decentralization is another aspect of structural reforms to adopt NPM as it creates more businesslike organizations with units of account (Diefenbach, 2009). It is said reforms lead to more reforms. Therefore, more structural reforms are expected in the public administration for the foreseeable future. The unprecedented innovations and developments in the information technology, globalization and global issues such as financial crisis and climate imply that the management style has to change over time to take into account the new or current insights. Nonetheless Mongkol (2011) contents that there are associated risks with the adoption of some private sector practices as proposed by NPM. Public and private sectors vary distinctively in terms of politics, statutory requirements, ethics, and social dimensions (Mongkol, 2011). In most cases, public entities operate in a more turbulent political environment as compared to private firms.

\subsubsection{Performance Measures}

The shift from bureaucratic processes to a managerialism in which quantification and justification of the expenditures are at the center of focus has accentuated performance measurements in the public arena (Diefenbach, 2009). The governments, researchers, audit and oversight bodies have channeled considerable efforts to develop reliable performance indicators to measure the outcome (Lapsley, 2008). The public service organization also adopted balanced scorecard and benchmarking as new techniques to identify some relationships and borrow ideas from different areas or disciplines (Diefenbach, 2009). However, availability of robust and appropriate measures to accurately evaluate performance is still a dilemma in the industry (Brinkerhoff \& Brinkerhoff, 2015). Some of the services provided by the government such as security cannot be quantified neither can they be forecasted accurately because of the uncertainty. The essence of the public administration is not to generate profits but to ensure the wellbeing of its citizens. Therefore some argue that the quality of services offered should be a priority and not the amount spent.

According to United Nation's department for international Development (DFID), change process to adopt NPM elements has been successful in some countries. The reforms in tax administration had significant impact in the Sub-Saharan African countries. The figures indicate that in the first phase of the program in Uganda, the tax to GDP ratio rose from $5.7 \%$ to $11 \%$. After a short period of stagnation, the ratio increased from 12.5 percent in 2005 to 13.8 percent in 2009. In Tanzania, the tax reform initiative supported by the United Kingdom saw the ratio rising from $12 \%$ in 2006 to $14.5 \%$ in 2008 . A similar improvement was observed in Rwanda where the percentage rose from $12.8 \%$ in 2006 to 13.8 in 2008 (Robinson, 2015). This is an indication that when NPM elements are well adopted, they are more likely to benefit the government and the public.

\section{NPM Model In Practice: The Case of Kenya \\ 3.1. Introduction}

Like many other African countries, Kenya has had a turbulent past characterized by corruption, poor service delivery, mismanagement of public resources, and sluggish or slowed economic growth. However in the past decade, the nation has seen some transformation in trade and leadership that has escalated economic trade. The conditions set by development partners, international donors such International Monetary Fund (IMF) as well as the pressure from the citizens to improve service delivery and ensure transparency have been the primary sources of transformation. This section discusses key changes in relation to Public Fund Management (PFM). Note that Kenya has two level of government: National and County Governments.

\subsection{Budgeting}

The public participation aspect of NPM has been adopted. The office of the Auditor general and the Office of the budget controller have been established as well as audit committees in state-owned enterprises. All public enterprises are now required to have an audit committee to assess and monitor the use of public funds and other resources within the organization. In response, County governments have established the committees to comply with the law. The New Constitution, promulgated in 2010 calls for public participation in the budget making process. The Cabinet Secretary of the Treasury has to obtain the views of the citizens when coming up with the budget. The reform fosters transparency and has significantly reduced fund wastage. 


\subsection{Institutionalism and Financial Reporting}

The public sector has adopted the International Public Sector Accounting Standards (IPSAS) in the preparation of financial statements. The ministries at the national government, agencies and departments as well as the county government are now using IPSAS to prepare financial statements. Even though the system is still cash basis, the financial reports provide additional disclosures on pending receivables, bills, and fixed assets. The objective is to move towards accrual basis accounting in the near future which is expected to enhance accountability.

Public institutions have undergone reforms with more commissions being created to enhance transparency. For instance, the director generals and other critical positions in the National Treasury have been filled in strict compliance with the law based on the requirements of each position. The reform builds requisite set of skills so as to improve the management of public fund. The administration has also been restructured and decentralized with the creation of county governments in 2010 under the New Constitution. Several function, personnel and budget of some departments such as health have been transferred to the county governments. To combat corruption, an independent anti-corruption commission was established in August 2011.

\subsection{Integrated Financial Management Information System (IFMIS)}

The system is being used at the National Government and some government agencies such as I-TAX for Kenya Revenue Authority (KRA). The roll out to the County governments as well as the integration of IFMIS with internet and mobile banking by the Central Bank of Kenya (CBK) is underway. E-procurement has also been integrated into the system to allow for online procurement of goods as service with the objective of increasing competition for the tenders by opening the platform for all interested parties. It also aims at countering corruption that had been experienced for long time when it comes to awarding tenders. This is a privatization aspect of NPM that allows competitive bidding that eventually ensures delivery of quality services to the public. It is also part of structural reforms to see the government adopting the most technologies to foster efficiency and effectiveness.

\subsection{The Rule of Law}

Over the past five years various legislations such as the Public Finance Management Act (for the National Government), the public procurement and Disposal Act, the public Finance Management regulations 2015 (for County Governments), and the Public Audit Act have been enacted. The laws have significantly increased transparency and accountability in the management of public funds as they provide clear procedures, processes and define roles for individuals holding certain positions. For instance, the Public Audit Act of 2015 outlines the duties and powers of the Auditor General that gives him or her right to audit all activities and operation of public entities and offer recommendations or suggest a corrective action.

\section{The Impact of NPM on Public Governance}

\subsection{Transparency and Accountability}

Elements of NPM such as performance based budgeting, accrual accounting and flexibility in the public administration fosters transparency and accountability. The ideas emphasize on outcomes, results, and holding the responsible authorities accountable of their decisions (Ashraf \& Uddin, 2016). They advocate for greater openness in the expenditure of public finances to enhance their scrutiny. Open budget preparation, execution as well as reporting enhance fiscal transparency (Irwin, 2013). With performance-based budgeting, resources are allocated depending on the success of each program or project so as to achieve measurable outcomes. The active involvement of all stakeholders including the public in the budge preparation and policy formulation fosters openness (Bovaird \& Loffler, 2001).

With NPM in practice, public management has become a collective process where various individuals including the politicians, elected officials, civil servants, advisors, and stakeholders interact with the objective of maximizing social advantage to the public (Bovaird \& Loffler, 2001). The sector is moving towards developing local governance and authorities and allowing the local communities to plan and manage their affairs with little interference from the state or national governments. Unlike from a traditional perspective, the role of citizens in public finance has gone beyond being mere voters, constituents, clients, or customers to becoming co-creators, problem-solvers, and governors who actively participate in the production of what is of high value and good to the whole population (Hodgkinson et al., 2017). In the new public management, the elected officials and the managers assume the function of creating public value to effectively address the elements as per the needs of the citizens (Fatemi \& Behmanesh, 2012). They help in building cross-sector collaborations and partnerships to attain mutually agreed goals and not just the objectives of the leaders and managers.

Accrual accounting enhances internal and external transparency as well as accountability of the state entities. It helps in the identification of total costs of each activity or operation thus aiding the decision making process regarding allocation of resources, coordination and control. Though disputable, technology has also been found to have a positive impact on the public management. After testing three hypotheses regarding the management in public administration, it was evident that current developments such as Government Integrated Financial 
Management Information System (GIFMIS) and Integrated Payroll and Personnel Information System (IPPIS) have had a positive impact on transparency and openness in the public sector (Alobari et al. 2017). In a review of the effect of new public management reforms in central and Eastern Europe; Dan and Pollitt (2015) also find that Common Assessment Framework (CAF) and Multi-annual Modernization Plans (MMPs) improved processes and efficiency. The tools fostered cultural changes that emphasized on results-based public management hence holding the leaders accountable.

\subsection{Agency Problem}

Implementation of general management leads to collision of values between the professional associates and the general managers (Lapsley, 2008). The conflict of interests between the management and shareholders is also more likely to occur. From a theoretical perspective, it is argued that public organizations should provide all relevant information to the citizens; but this is not the case in real-world. Information asymmetry still exists such that the management holds much information that may be required by the investors to make decisions. Therefore, some managers may decide to pursue personal agendas or serve the interests of few individuals in the society. Christensen \& Lægreid (2001) holds that in some cases, NPM can inspire contradictory reforms such as centralization and devolution. In support, Kartalis et al. (2016) argue that the NPM can contribute to shifting organizational boundaries since the reforms may introduce conflicting values and objectives that create tensions among actors. For instance, conflict between business and cultural values is more like to emerge if economic capital conflicts with political and cultural capitals.

\subsection{Increased Government Expenditure}

The NPM model comes at a cost. Most of its elements and principals call for additional expenditure. The introduction of information systems, management consultants, public participation process, and general managers or directors implies that the government needs to spend more. The establishment of additional bodies such as anticorruption commissions means more public servants hence increased salary expenditures. The operations by these commissions also call for additional funding. The success of NPM is also not guaranteed (Dunn \& Miller, 2007). Therefore, it is implementation also puts the country and its citizens at a risk of incurring losses due to program failure. For instance, in the UK Lapsley (2009), finds that the 'online for business' project that cost 25 million Sterling Pounds failed to deliver its objectives and was wound up after four years of its inception. He also adds that the expenditure on management consultants increased drastically from 1993 to 2006 after the arrival of NPM.

\section{Preconditions of NPM and Factors Affecting Its Implementation}

This section presents the preconditions for the success of NPM and the factors affecting the implementation of NPM reforms in the Developing Countries based on the reviewed articles.

\subsection{The Preconditions or Requirements for the Success of NPM}

It is argued that for a country to successfully and effectively implement all or part of the NPM framework elements, some pre-requisites need to be in place or fulfilled. This paper outlines effective judicial, administrative system and the capacity of the state as the main preconditions. Most developing nations are yet to meet these conditions hence facing challenges when implementing some of NPM principles.

\subsubsection{Effective Judicial System}

The NPM principles and elements are market-oriented hence need for substantial economic development level as well as effective market operations. It thus implies that there must a judicial system to provide the rule of law since markets are more likely to be ineffective without policies and regulations (Sarker, 2006). For instance, the rule of law is necessary in ensuring that parties comply with business contracts and meet their obligations timely. Similarly, a sound judicial system guarantees and solves conflicts or differences in an objective and independent way. NPM is also characterized by a lot of policies, rules, and regulations for the politicians and public officials (Dunn \& Miller, 2007). It is through an effective autonomous judicial system that such laws are upheld.

\subsubsection{Efficient and Control-oriented administrative system}

The implementation of market-oriented models such as NPM requires administrative processes that ensure an efficient and externally controlled system. The state should have the ability to fulfill basic administrative roles and prove fundamental public goods and services. In their article, Christensen \& Lægreid (2001) notes that the state would be unable to implement some NPM principles such as privatization and contracting out if it cannot discharge the minimal functions like provision of basic human services, judiciary, and economic infrastructure. The control acts as the foundation upon which a formal, honest and rule-based public sector is formed. Sarker (2006) asserts that such system allows managers to gain new skills, build trust and confidence between the government and the citizens, and internalize or instill proper ethical behavior. There politicians among other public officials need to first control inputs, account for cash, adhere to uniform rules before shifting the focus on outputs and costs. 


\subsubsection{The State Capacity}

The capacity is the ability of the nation to decisively take any measure of reform. It is characterized by technical, institutional and political factors. The implementation of NPM and the potential outcome are determined by the interplay between environmental factors, the national administrative policy and its culture (Christensen \& Lægreid, 2001). From an institutional point of view, the capacity of a country is marked by its ability to uphold governmental authority, legislate and put into practice laws and at the same time hold the public officials accountable (Sarker, 2006). Politically, the country should be in a position to mediate conflict and respond to the demands of the citizens. It should allow the interests of the citizens to be represented and offer them opportunities to take part in political matters at different levels to enhance political stability and promote the state's legitimacy (Sarker, 2006). For instance, the study by the United Nations holds that in the process of reforming tax administration, Sierra Leone and Zambia showed less progress in tax to GDP ratios due to capacity constraints and the inability to overcome policy bottlenecks (Robinson, 2015).

\subsection{Factors Affecting the Implementation of NPM Reforms in the Developing Countries 5.2.1. Availability of Resources}

Resources include human personnel, facilities, information on how to put the reforms in practice as well as the authority to implement the changes as intended (Grizzle \& Pettijohn, 2002). According to World Bank, the agencies require specialized staff to plan, budget, and evaluate the outcome of each reform for the implementation process to be successful (Moynihan \& Beazley, 2016). Regarding performance-based budgeting, there is need to employ consultants and other external experts to assist in the identification of the projects and establish performance measures. Resources are also required to develop new routines for data-collection to capture results that are downstream in the events that link products of the project to the societal benefits (Grizzle \& Pettijohn, 2002). The International Monetary Fund (IMF) contents that due to inadequate resources, many countries have been unable to establish and maintain control over efforts to define and collect data hence leading to data corruption (Robinson \& Last, 2009). For instance, in country Kenya; the government has been unable to fully implement and conduct performance audit on all public-funded projects and effectively roll out public participation in budgeting process because of limited resources.

\subsubsection{The dispositions or attitude of policy implementers}

The dispositions and attitudes of individuals implementing the budget or relating policies is the extent to which a body of policy makers is likely to favor enactment by putting in place strategies to ensure the success of the whole process. The individuals include politicians or law makers, civil servants, and all other stakeholders. According to Grizzle \& Pettijohn (2002), the dispositions may be grounded in the organizational or national culture because the general culture is essential both in understanding the environment that would aid the passage of reforms to determining the implementation procedures.

In their study, Mauro et al. (2019) finds that the human dimensions of the practice are some of the challenging set of factors that affect the success of national reforms. They assert that the intensity reforms such as performancebased budgeting are heavily explained by these dimensions due to their criticality in building a performance culture with the involvement of other stakeholders. A survey in The Organization for Economic Co-operation and Development (OECD) countries also reveals that negative attitude by the actors towards changes NPM reforms (Sterck \& Scheers, 2006). For instance, in some cases, public servants and politicians exhibit strong resistance to proposed amendments, making it difficult to put it in practice. In other circumstances, policymakers fail to pass the laws so that they can pursue personal interests.

\subsubsection{The Professional Societies}

The strong groupings of professionals in the current society have been identified as potential barriers to implementation of NPM framework (Pollitt et al., 2007; Groot \& Budding, 2008). The bodies have gained power and authority to an extent of defining criteria of measuring performance and the manner in which problems should be handled (Pollitt et al., 2007). As a result, the professional associations have set process and procedures that enable them to escape external scrutiny that requires them to account for their actions. In practices the groups have opposed and resisted some changes such as performance-based budgeting. Groot \& Budding (2008) concurs with the findings by stating that due to the robust nature of professional societies, it is anticipated that NPM reforms will continue to face challenges with strong opposition from public servants.

\subsubsection{Bureaucratic Structure}

Bureaucratic structure is made up of two main features; standard operating procedures and organizational fragmentation. Arellano-Gault \& Gil-García (2004) holds that policy constraints in developing nations affect and in some instance neutralize the promised outcome of NPM reforms. Besides general political, organizational and legal factors; political managers in most developing nations have limited discretion when making decisions. The countries also lack a strong history of public service ethics thus being exposed to greater risks functional imbalance (Ashraf \& Uddin, 2016).

Grizzle \& Pettijohn (2002), state that organizational fragmentation affects the necessary coordination needed 
to successfully implement a complex policy that calls for the participation of many individuals. It also waste limited resources, creates confusion, and inhibits change (Crain \& O'Roark, 2004). NPM model requires the involvement of all governments and the public. Therefore, some procedures such as negotiation for what makes up an acceptable set of performance indicators for a program can be frustrating for agencies (Sterck \& Scheers, 2006). The complex budget procedures, format and transfer of authority have also been found to be a source of dysfunctional consequences for the implementation of the proposed reforms (Huque \& Zafarullah, 2014).

In a fragmented or politically divided nation, the implementation process is more likely to experience disagreement regarding the objective, priorities and the identification of appropriate performance measures to account for all relevant issues (Mauro et al., 2019). This has been evident in democratic republics such as Kenya where sometimes member of the parliament as well as the public are divided along political lines making it difficult to reach a common ground where both parties are satisfied. As a result key laws and policies to enhance NPM model have failed to pass. Bureaucratic structures have also been blamed for increased levels of corruption in many countries. Politicians and public officials use their power and authority to enrich themselves with public funds that leave the state without resource to run its operations.

\section{Conclusions and Recommendations}

This section offers recommendations, study limitations and suggestions for further research; and conclusion.

\subsection{Recommendations}

\subsubsection{Institutionalization of Code of Ethics and Conduct}

Public institutions and organizations should adopt and put into practice the compliance programs and codes of conduct to shape organizational culture. Culture and organizational behavior plays a huge role in establishing changes. How people react and works towards achieving the proposed reforms determines the success of those reforms. A universal organization culture and structure across public institutions allows for benchmarking, performance measurement, and a unified change process. Some of NPM proposals such as performance-based budgeting have worked best in countries with supportive organizational culture. Therefore, instilling a cultural that paves way for organizational change in the public sector can be an effective strategy to break resistance and shift from traditional administrative systems. The culture can be attained by fostering universal work ethics and values in all ministries, public departments, State-owned enterprises and agencies.

\subsubsection{Balancing politics and bureaucracies}

Balancing political and bureaucratic support eliminates biasness and personal interests hence vital in promoting reforms such as participative or performance-based budgeting. It is clear that reforms in the public sector rely heavily on a political champion. However, more often, political support for policy changes leads to disruption, discontinuity, and backsliding due to conflict of interest and political differences. Aspects such as institutionalized performance budgeting and public involvement among developing nations would help override the variations of interests among politicians and other law makers. Additionally, public participation should be fostered at national and lower-level governments. The civil society and the whole public should take the responsibility of monitoring all the government projects both internally and externally to ensure they are accomplished as per the plan and meets the set standards. The move would see governments focusing on the needs of the public rather than personal interests.

\subsubsection{Effective law Enforcement}

Having laws inform of a constitution is not enough. How well it is enforced is a primary concern as further as reforms are concerned. Despite passing policies, and regulations to control and regulate operations in public administration; most of these rules especially in developing countries are not put into practice. The laws exist theoretically or in papers but not in practice. Therefore, the nations should implement and enforce the laws to ensure that actual behaviors and operations correspond to the statutory or legal requirements. The responsible institutions like the judiciary should be strengthened enough and given authority to work independently from other arms of the government and commissions to ensure that the laws are enforced to the letter. In addition to law enforcement, flexibility in the public administration to put into consideration the public demands and suggestions by involving them in the decision making process can also accelerate national reforms.

\subsubsection{Implementing NPM Principles or Reforms in Phases}

The complexity of NPM both in theory and in practice requires a multi-dimensional approach to determine its applicability in a particular country. Its implementation does not guarantee success; neither does it solve all problems in the public administration. Developing countries are faced with the challenge of limited resources ranging from financial to technology. It is thus recommendable that they adopt the NPM reforms slowly by slowly or in phases to avoid the risk of failure and capitalize on the scarce opportunities in the global world. The process should be evolutionary and not revolutionary with cost-benefit analysis coming into play. Quality and the impact of the changes should be given a priority. Pilot projects or benchmarking countries with similar characteristics prior to the enforcement of the reforms would also ensure their success and reduce the risks of failure. 


\subsection{Study Limitations and Suggestions for Further Research}

The study heavily depends on the secondary information as it reviews the existing literature. Therefore, some of the findings may not present the current situation because of the continuous changing global environmental and governmental policies. Secondly, since countries have different laws and regulations, some of the identified factors may not be applicable to all developing nations.

In this regard, it is suggested that a similar research be conducted using primary data and information to ascertain the results and findings. As noted in the paper, majority of developing nations have adopted NPM model due to pressure from international donors; a study may also be carried out to investigate the specific impact of the framework on public governance.

\subsection{Conclusion}

The NPM reforms aim at making the public sector lean and more competitive. It offer choice of flexibility, value for money and fosters transparency and accountability thus making the public administration more responsive to the needs of the citizens. However, it requires a lot of resources including personnel, technology, and finance for effective implementation since it calls for both structural and cultural changes at a national as well as organizational level. As a result majority of developing countries such as Kenya have been unable to fully put into practice the NPM framework. Nonetheless, the few aspects that have been implemented such as public participation in budget formulation and competitive bidding have had a positive impact in service delivery. To some extent, the involvement of the public has seen the government considering the needs of the citizens rather than political interest.

The transfer of policies from best practices or outcomes as observed in the developed countries to developing nations is trendy and is expected to continue because of increased pressure from international donor agencies. Therefore, developing countries will continue adopting NPM model into their systems. Nevertheless, the success of such transfers is subject to the macroeconomic environment, transparency in the public policy process, availability of human and financial resources and more importantly the manner in which the nations adopt and put NPM into practice. Strategies applied by the NPM-archetype countries may not be effectiveness for the importernations because of cultural, structural and behavioral differences. The European Union member states have the same purpose at the leadership level such as social protection, great employment, sustainable economic growth, conservation of environment, gender equity and equality, and improving the living standards. But because of the subsidiarity and proportionality principle, each member state may come up with a suitable public management approach to attain the set objectives. It does imply that even developing countries should not necessarily import the entire framework as implemented in the developed countries. Rather, they should assess their capability, administrative structure and culture to adopt NPM in a style that ensures effectiveness, efficiency, economy, and ethics in public management while considering social, cultural, and political environment.

The reliable judicial, administrative, and state capacity is some of the pre-requisites for effective implementation of NPM. Breach of contracts and lack of clear policies to define duties and responsibilities in the public administration have interfered with some NPM features such as performance based budgeting. The elements of NPM such as privatization and contracting out require well established laws and regulations as well as bodies to enforce them. Beside the expected positive outcome such as improved service delivery; some aspects like introduction of general managers pose the challenge of conflicting interest between the managers and the stakeholder. In other words, the results of NPM framework are uncertain to some extent. Adopting the principles in phases can be a better strategy to avoid and mitigate some of the risks. Ethics as part of the organization culture can also foster NPM reforms. Due to limited resources, the country needs to focus on a more valuable package that is likely to have a great impact. The quality of the reform is more important than the, pace and scale/coverage.

\section{Bio data}

Antony Wafula Wanyonyi was born July 1990, in Nairobi Kenya. He obtained a Bachelor degree in commerce at The University of Nairobi, School of Business in 2015 majoring in Accounting and Finance. The author has a significant experience in public administration having worked as an accountant in the Public Service. At the time of publication, he was pursuing Master of Science in Audit at Nanjing Audit University in the Peoples Republic of China.

\section{Acknowledgment}

My sincere appreciation goes to the management and the whole fraternity of Nanjing Audit University (NAU) for a wonderful environment and experience that enable me to complete this paper. I extent my appreciation to my program sponsors, The Ministry of Commerce (MOFCOM) of PR China for granting me a learning opportunity. Special thanks to Prof. Wu Kai of Nanjing Audit University who provided insight and professional guidance throughout the study. Your comments and advice largely improved the final manuscript. I would also like to show my gratitude to the dean of School of International Exchange (SIE), Mr. L.J Cheng and to our soft hearted class 
coordinator, Tang Xiaoyun (Effine) for sharing their pearls of wisdom and encouragement with me during the course of the study. Your commitment and dedication are virtues to admire.

The completion of this study could not have been accomplished without the support of my classmates; thumbs up to the NAU International Students Class of 2018, Masters of Audit. Heartfelt thanks to my parents and my family at large. To My Dad, Mr. Anzelimo Khaemba Wanyonyi you were very supportive and this is a special dedication. You were alive when I started this study but it is unfortunate that you couldn't live long to have a glimpse of the final document. Hope your soul is at peace. To my mother, Mrs. Agnes Wanyonyi the struggle that you gone through to ensure that I excel in all life aspects will never be forgotten. Thanks to Mr. Edwin Wekesa, a long-term friend for assistance with cases and other resourceful materials. Your encouragement when the times got rough are much appreciated and duly noted.

$\begin{array}{ll}\text { Abbreviations } & \\ \text { NPM } & \text { New Public Management } \\ \text { GDP } & \text { Gross Domestic Product } \\ \text { UK } & \text { United Kingdom } \\ \text { IMF } & \text { International Monetary Fund } \\ \text { IPSAS } & \text { International Public Sector Accounting Standards } \\ \text { KRA } & \text { Kenya Revenue Authority } \\ \text { CBK } & \text { Central Bank of Kenya } \\ \text { CAF } & \text { Common Assessment Framework } \\ \text { PBB } & \text { Performance-Based Budgeting } \\ \text { OECD } & \text { Organization for Economic Co-operation and Development }\end{array}$

\section{References}

Alobari, C., Paago, J. K., Naenwi, M., \& Tordee, B. (2017). Financial Management and the Public Sector: Trend, Problems and Prospects. Financial Management and the Public Sector: Trend, Problems and Prospects (October 1, 2017). Equatorial Journal of Finance and Management Sciences, 2(2), 34-45.

Arellano-Gault, D., \& Gil-García, J. R. (2004). PUBLIC MANAGEMENT POLICY AND ACCOUNTABILITY IN LATIN AMERICA: PERFORMANCE-ORIENTED BUDGETING IN COLOMBIA, MEXICO, AND VENEZUELA. International Public Management Journal, 7(1), 49-71.

Ashraf, J., \& Uddin, S. (2016). New public management, cost savings and regressive effects: A case from a less developed country. Critical Perspectives on Accounting, 41, 18-33.

Bovaird, T., \& Loffler, E. (2001). Emerging trends in public management and governance. BBS Teaching and Research Review, 5, 1-10.

Brinkerhoff, D. W., \& Brinkerhoff, J. M. (2015). Public sector management reform in developing countries: Perspectives beyond NPM orthodoxy. Public Administration and Development, 35(4), 222-237.

Christensen, T., \& Lægreid, P (2001). New Public Management: The effects of contractualism and devolution on political control. Public Management Review, 3(1), 73-94.

Constitution of Kenya, Public Finance Management Act, (2015). Principles and Frameworks of public finance.

Crain, W. M., \& O'Roark, J. B. (2004). The impact of performance-based budgeting on state fiscal performance. Economics of governance, 5(2), 167-186.

Dan, S., \& Pollitt, C. (2015). NPM Can Work: An optimistic review of the impact of New Public Management reforms in central and Eastern Europe. Public Management Review, 17(9), 1305-1332.

Diefenbach, T. (2009). New public management in public sector organizations: the dark sides of managerialistic 'enlightenment'. Public administration, 87(4), 892-909.

Dunn, W. N., \& Miller, D. Y. (2007). A critique of the new public management and the neo-Weberian state: advancing a critical theory of administrative reform. Public organization review, 7(4), 345-358.

Fatemi, M., \& Behmanesh, M. R. (2012). New public management approach and accountability. International Journal of Management, Economics and Social Sciences (IJMESS), 1(2), 42-49.

Grizzle, G. A., \& Pettijohn, C. D. (2002). Implementing Performance-Based Program Budgeting: A SystemDynamics Perspective. Public Administration Review, 62(1), 51-62.

Groot, T., \& Budding, T. (2008). New public management's current issues and future prospects. Financial Accountability \& Management, 24(1), 1-13.

Gruening, G. (2001). Origin and theoretical basis of New Public Management. International public management journal, 4(1), 1-25

Hammerschmid, G., Van de Walle, S., Andrews, R., \& Mostafa, A. M. S. (2017). New public management reforms in Europe and their effects: Findings from a 20-country top executive survey. International Review of Administrative Sciences, 0020852317751632.

Haque, M. S. (2006). Modernising government: The way forward, an analysis. International Review of 
Administrative Sciences, 72(3), 319-325.

Hodgkinson, I. R., Hannibal, C., Keating, B. W., Chester Buxton, R., \& Bateman, N. (2017). Toward a public service management: past, present, and future directions. Journal of service management, 28(5), 998-1023.

Huque, A. S., \& Zafarullah, H. (2014). Public management reform in developing countries. Public Sector Reforms in Developing Countries, 10-22. doi: 10.4324/9780203797587-2

Irwin, M. T. (2013). Shining a light on the mysteries of State: The origins of fiscal transparency in Western Europe (No. 13-219). International Monetary Fund.

Kartalis, N., Tsamenyi, M., \& Jayasinghe, K. (2016). Accounting in new public management (NPM) and shifting organizational boundaries: Evidence from the Greek Show Caves. Accounting, Auditing \& Accountability Journal, 29(2), 248-277.

Lapsley, I. (2008). The NPM agenda: back to the future. Financial accountability \& management, 24(1), 77-96.

Lapsley, I. (2009). New public management: The cruellest invention of the human spirit? 1. Abacus, 45(1), 1-21.

Mathiasen, D. G. (1999). The new public management and its critics. International public management journal, 2(1), 90-111.

Mauro, S. G., Cinquini, L., \& Pianezzi, D. (2019). New Public Management between reality and illusion: Analyzing the validity of performance-based budgeting. The British Accounting Review.

Mongkol, K. (2011). The critical review of new public management model and its criticisms. Research Journal of Business Management, 5(1), 35-43.

Moynihan, D., \& Beazley, I. (2016). Toward next-generation performance budgeting: Lessons from the experiences of seven reforming countries. The World Bank.

Oehler-Sincai, I. M. (2008). Strengths and weaknesses of the New Public Management (NPM)-cross-sectional and longitudinal analysis.

Pollitt, C. (2001). Clarifying convergence. Striking similarities and durable differences in public management reform. Public management review, 3(4), 471-492.

Pollitt, C., Van Thiel, S., \& Homburg, V. (Eds.). (2007). New public management in Europe. Basingstoke: Palgrave Macmillan.

Public Finance Management Act, (2015). Available at http://www.parliament.go.ke/sites/default/files/201705/Legal_Notice_No._34_National_Govt_Regu.pdf

Robinson, M., \& Last, M. D. (2009). A basic model of performance-based budgeting. International Monetary Fund.

Robinson. M, (2015). From Old Administration to the New Public service: Implications for public Sector reform in Developing Countries. Global Centre for Public Service excellence. Retrieved from https://www.undp.org/content/dam/undp/library/capacity-development/English/Singapore\%20Centre/PSReform_Paper.pdf

Sarker E. A. (2006). New public management in developing countries: An analysis of success and failure with particular reference to Singapore and Bangladesh. International Journal of Public Sector Management, 19(2), 180-203.

Sterck, M., \& Scheers, B. (2006). Trends in performance budgeting in seven OECD countries. Public performance \& management review, 30(1), 47-72.

Van de Walle, S., \& Hammerschmid, G. (2011). The Impact of the New Public Management: Challenges for Coordination and Cohesion in European Public Sectors. Halduskultuur, 12(2). 